\title{
A DEFINIÇÃO DE EVASÃO E SUAS IMPLICAÇÕES (LIMITES) PARA AS POLÍTICAS DE EDUCAÇÃO SUPERIOR
}

\author{
LEONARDO BARBOSA E SILVA ${ }^{1}$ \\ ORCID: https://orcid.org/0000-0002-1528-1445 \\ ALEXSANDRO SOUZA MARIANO ${ }^{2}$ \\ ORCID: https://orcid.org/0000-0002-2796-1894
}

\begin{abstract}
RESUMO: As políticas públicas partem de diagnósticos da realidade que, com alguma frequência, utilizam indicadores sociais e registros administrativos. Os sucessos da ação pública e das ferramentas de diagnose dependem, dentre outras coisas, de uma definição adequada do fenômeno a ser enfrentado. Este artigo objetiva problematizar a definição de evasão na educação superior vigente e oficial utilizada pelo INEP/MEC, a partir de seu documento orientador "Metodologia de Cálculo dos Indicadores de Fluxo da Educação Superior", de 2017, e apontar seus limites e implicações. Para lograr êxito, foi mobilizada uma pesquisa documental bifurcada em métodos de análise documental para textos governamentais e de análise de dados para o Censo da Educação Superior. Para a apresentação das reflexões, optou-se, inicialmente, por apontar a importância que a evasão tem em várias políticas públicas para a educação superior. Posteriormente, tem-se a análise propriamente do objeto deste artigo. Os resultados alcançados sinalizam para a presença de limites na capacidade de expressar o fenômeno e, por conseguinte, instrumentalizar as políticas públicas adequadas ao problema público, sobretudo porque a definição vigente não se ocupa das motivações, ignora os reingressos ao considerar o abandono como ato sempre terminativo, não se compromete com uma análise longitudinal e não dialoga adequadamente com as finalidades da educação superior estabelecidas pela Lei de Diretrizes e Bases.
\end{abstract}

Palavras-chave: Evasão, Educação Superior, INEP, Políticas Públicas.

\section{DEFINITION OF DROPOUT AND ITS IMPLICATIONS (LIMITS) FOR HIGHER EDUCATION POLICIES}

\begin{abstract}
Public policies are based on diagnoses of reality that, with some frequency, use social indicators and administrative records. The success of public action and of diagnostic tools depends, among other things, on an adequate definition of the phenomenon to be addressed. This article aims to problematize the current and official definition of dropout in higher education used by INEP/MEC, based on its guiding document "Methodology for Calculating Flow Indicators in Higher Education" of
\end{abstract}

\footnotetext{
${ }^{1}$ Univerisdade Federal de Uberlândia (UFU). Uberlândia, MG, Brasil. barbosaesilva.leonardo@ufu.br.

${ }^{2}$ Univerisdade Federal de Uberlândia (UFU). Uberlândia, MG, Brasil. alexsandro@prograd.ufu.br. Educação em Revista|Belo Horizonte|v.37|e26524|2021
} 
2017, and point out its limits and implications. To achieve success, a documentary research was mobilized, bifurcated in methods of document analysis for government texts and data analysis for the Census of Higher Education. For the presentation of the reflections, it was opted, initially, to point out the importance evasion has in several public policies for higher education. Later on, there is the actual analysis of the subject of this article. The results achieved signal the presence of limits in the ability to express the phenomenon and, consequently, to instrumentalize public policies appropriate to the public problem, especially because the current definition does not deal with the motivations, ignores the reentries by considering the dropout as an act always terminative, does not commit to a longitudinal analysis and does not adequately dialogue with the purposes of higher education established by the Law of Directives and Bases.

Key-words: Evasion, Higher Education, INEP, Public Policies.

\section{DEFINICIÓN DE EVASIÓN Y SUS IMPLICACIONES (LÍMITES) PARA LAS POLÍTICAS DE EDUCACIÓN SUPERIOR}

RESÚMEN: Las políticas públicas parten de diagnósticos de la realidad que, con cierta frecuencia, utilizan indicadores sociales y registros administrativos. Los éxitos de la acción pública y las herramientas de diagnóstico dependen, entre otras cosas, de una adecuada definición del fenómeno que será enfrentado. Este artículo tiene como objetivo problematizar la definición de evasión en la educación superior vigente y oficial utilizada por INEP / MEC, a partir de su documento orientador "Metodología para el cálculo de los indicadores de flujo de la educación superior" de 2017, y señalar sus límites e implicaciones. Para lograr el éxito, se movilizó una investigación documental bifurcada em métodos de análisis de documentos para textos gubernamentales y de análisis de datos para el Censo de la Educación Superior. Para la presentación de las reflexiones, inicialmente se eligió señalar la importancia que tiene la evasión en diversas políticas públicas para la educación superior. Posteriormente, se realiza un análisis del objeto de este artículo. Los resultados alcanzados apuntan para la presencia de límites en la capacidad de expresar el fenómeno y, por lo tanto, instrumentalizar políticas públicas adecuadas al problema público, sobre todo porque la definición vigente no se ocupa de las motivaciones, ignora los reingresos al considerar el abandono como un acto siempre terminativo, no se compromete con un análisis longitudinal y no dialoga adecuadamente con los propósitos de la educación superior establecidos por la Ley de Directrices y Bases.

Palabras clave: Evasión, Educación Superior, INEP, Políticas Públicas. 


\section{INTRODUÇÃO}

A educação superior brasileira é, recorrentemente, objeto de avaliações formais e informais que mobilizam a evasão como variável de destaque. Sua participação é negativa, ou seja, quanto maior a presença de casos, pior é a percepção sobre os resultados da instituição. Para os órgãos públicos que acompanham o fenômeno, o mesmo pode ser quantificado ou mensurado a partir de indicadores (INEP, 2017; TCU; MEC, 2004) que apontam claramente a relação entre as taxas de evadidos(as) e o sucesso institucional. Por seu turno, a produção acadêmica (BAGGI; LOPES, 2011) tem produzido reflexões que, em alguns aspectos, replicam a percepção negativa sobre a evasão que é emanada dos órgãos públicos. No entanto, uma parte das reflexões científicas tem-se centrado na crítica das definições vigentes (BUENO, 1993; COIMBRA; COSTA; SILVA, 2020; LIMA JUNIOR et al., 2019; RISTOFF, 1999).

As definições, tanto para órgãos públicos quanto para o universo acadêmico, são muito importantes porque estabelecem a baliza a partir da qual o fenômeno estudado será quantificado, analisado e avaliado. Quando se define um fenômeno quantificável, ato contínuo se produzem ferramentas de mensuração. Elas podem ser simples estatísticas públicas (registros administrativos) ou sofisticados indicadores (JANNUZZI, 2001), mas sempre tomarão a definição como ponto de partida da construção do mensurador (FREITAS, 2016). Por conseguinte, uma vez utilizado o indicador, ele gerará dados importantes para o diagnóstico da situação e instrumentalizará a decisão da gestão pública. Portanto, a definição de um fenômeno é estratégica para o bom resultado de uma política pública.

O objetivo deste trabalho é justamente problematizar a definição de evasão oficialmente vigente e anunciada pelo INEP a partir de seu documento orientador "Metodologia de Cálculo dos Indicadores de Fluxo da Educação Superior" (INEP, 2017), com ênfase num aspecto especial: encontrar as insuficiências que dificultam a academia e a gestão pública de fazerem o enfrentamento do abandono na educação superior. A pergunta a ser respondida seria: a definição vigente é apropriada ao fenômeno do abandono instrumentalizando adequadamente as políticas públicas? Para respondê-la, optou-se por uma pesquisa documental desdobrada em dois métodos: a análise de documentos e a análise de dados. Para o primeiro caso, contaram como corpus documental os textos oficiais do governo federal que definem ou usam a evasão como variável na organização de políticas públicas. Para o segundo caso, foram usados microdados do Censo da Educação Superior dos anos de 2010, 2012 e 2017. Foram fundidos os bancos de 2010 e 2012, assim como os de 2010 e 2017, para que fosse possível observar a presença de estudantes "desvinculados do curso" em 2010 nos outros dois anos estudados. Para o controle do fluxo de um ano para outro, fez-se uso da variável "CO_ALUNO”, cujo conteúdo é um código de identificação individual e permanente atribuído pelo INEP.

A apresentação dos resultados, na seção que antecede as conclusões, será acompanhada de um debate prévio sobre o lugar da evasão nas políticas da educação superior, bem como das ponderações acerca da definição do fenômeno pelo governo federal. Ao término, poder-se-á perceber que, em boa medida, a caracterização vigente e oficial da evasão na educação superior é inadequada e, portanto, compromete a construção de indicadores, diagnósticos e políticas públicas. A constatação induz à necessidade de revisão da definição que leve em consideração a especificação do problema público, discriminando o que se definirá a partir da natureza do objeto, da motivação e da temporalidade (o reingresso), observando-se sempre as finalidades da educação superior expressas na Lei de Diretrizes e Bases da Educação.

\section{O LUGAR DA EVASÃO NAS POLÍTICAS PARA O ENSINO SUPERIOR}

A evasão possui um papel de destaque nas políticas do Ministério da Educação (MEC) para o ensino superior. Apesar de não figurar textualmente na Lei de Diretrizes e Bases da Educação -LDB - (BRASIL, 1996), ela está subentendida nos princípios gerais quando se assevera a igualdade nas condições de permanência, induzindo à reflexão de que a perda do vínculo pode depender das desigualdades sociais; ou quando nas finalidades da educação superior se dedica um inciso para a diplomação, deixando claro que a conclusão com diploma é um fim desejado.

Não obstante, a evasão pode ser vista no Plano Nacional da Educação - PNE - (BRASIL, 2014). As duas ocorrências da expressão não estão alocadas nas partes referentes ao ensino superior. 
Todavia, nas metas 12 e 13, especificamente nas estratégias 12.3 e 13.8, o documento deixa transparecer o desejo de elevação gradual da conclusão média dos cursos de graduação, o que, por pressuposto, significaria reduzir os percentuais de estudantes evadidos. O Plano define metas e estratégias para orientar o desenvolvimento da educação por uma década. No varejo, o Conselho Nacional da Educação (CNE), o MEC e suas políticas são os responsáveis pela regulamentação e operacionalização das ações. Consultando as resoluções do CNE (MEC, 2018), não foi possível encontrar nenhuma que tratasse da evasão em particular. Já para o caso das políticas recentes do MEC, a expressão recebe maior atenção.

Este ainda não seria o caso do SINAES, o Sistema Nacional de Avaliação do Ensino Superior. A leitura da lei (BRASIL, 2004) que o instituiu não levaria à conclusão de que a evasão tem alguma centralidade no processo de avaliação do ensino superior, uma vez que o termo e seus congêneres (abandono) ou antônimos (conclusão, diplomação etc.) ali não aparecem. Poder-se-ia valer das expressões eficácia institucional e efetividade acadêmica como possíveis sinônimos da mera diplomação elevada. No entanto, uma leitura mais atenta encaminha outra percepção, pois deve-se considerar que estas expressões foram redigidas em claro alinhamento com

\footnotetext{
a promoção do aprofundamento dos compromissos e responsabilidades sociais das instituições de educação superior, por meio da valorização de sua missão pública, da promoção dos valores democráticos, do respeito à diferença e à diversidade, da afirmação da autonomia e da identidade institucional (BRASIL, 2004).
}

Por outro lado, a política de permanência desenvolvida pelo governo federal a partir dos anos 2000 guardou lugar de destaque para o enfrentamento da evasão na educação superior. No Plano Nacional de Assistência Estudantil (FONAPRACE/ANDIFES, 2007), documento preparatório para criação do PNAES (Programa Nacional de Assistência Estudantil), pode-se ver a preocupação evidente com a permanência e a evasão. Essa expressão aparece nove vezes, normalmente associada aos custos públicos implicados, à representação de desperdícios de recursos, aos nexos com a retenção e ao comprometimento do direito à educação. Dois objetivos específicos citam-na textualmente, quando se compromete em:

\footnotetext{
contribuir para aumentar a eficiência e a eficácia do sistema universitário, prevenindo e erradicando a retenção e a evasão; [e] [...] definir um sistema de avaliação dos programas e projetos de assistência estudantil por meio da adoção de indicadores quantitativos e qualitativos para análise das relações entre assistência e evasão, assistência e rendimento acadêmico (FONAPRACE/ANDIFES, 2007).
}

Deste plano nasceu o PNAES, criado em 2007 (BRASIL, 2007b), constituindo-se como a principal ação de assistência estudantil do País, dada a sua abrangência (todas as IFES) e o seu orçamento (volume próximo a $\mathrm{R} \$ 1$ bilhão/ano em 2016). Até o nascimento do PNAES, toda a história da assistência estudantil no Brasil tinha sido retratada como um processo irregular, com avanços e retrocessos, não necessariamente incremental e que encontra seu ápice com a implementação desse programa (CROSARA; BARBOSA E SILVA, 2020), primeiramente como portaria (BRASIL, 2007b) e depois como decreto (BRASIL, 2010b). Atualmente, além de sua importância para a democratização da permanência, ele também parece servir ao enfrentamento da evasão e da conquista do "sucesso acadêmico" representado pela diplomação.

No mesmo ano de 2007, outro programa governamental direcionado à educação superior foi implementado em diálogo direto com a evasão. Trata-se do REUNI (BRASIL, 2007a), responsável pela expansão do sistema federal, ampliando vagas, cursos e instituições. Além disto, promoveu um importante processo de interiorização e democratização do acesso (MARQUES; CEPÊDA, 2012). Seu marco regulatório, o Decreto n ${ }^{\circ}$ 6.096/2007, instituiu o Programa de Apoio a Planos de Reestruturação e Expansão das Universidades Federais e trouxe como uma de suas diretrizes a "redução das taxas de evasão, ocupação de vagas ociosas e aumento de vagas de ingresso, especialmente no período noturno" (BRASIL, 2007a). Desta feita, fica evidente que houve uma preocupação da gestão pública em garantir que o processo de expansão fosse acompanhado da ampliação das condições de permanência, duelando com o abandono e ampliando as taxas de conclusão. 
Há uma outra dimensão muito importante das políticas de educação superior em que a evasão recebe destaque e que, via de regra, é olvidada pela produção acadêmica. Trata-se do financiamento, correntemente efetuado através de três fontes de recursos: aqueles oriundos do Tesouro Federal, os arrecadados diretamente por prestação de serviços e os provenientes de contratos e convênios com órgãos públicos e privados. Das três fontes, somente aqueles recursos originários do Tesouro Federal guardam relação direta com o objeto deste artigo, pois estão, de alguma forma, influenciados pela evasão ${ }^{3}$.

Entretanto, cabe lembrar que tais recursos podem ser divididos em duas fatias muito distintas: aquela responsável pela folha de pagamentos, pensões e aposentadorias, e aquela destinada ao custeio e despesas de capital das IFES. Ambas têm seu volume total definido segundo a lógica inercial ou incremental, ou seja, usa-se o orçamento do ano anterior como baliza, associando-se incrementos caso necessário. Todavia, a distribuição dos recursos da segunda fração, de custeio e capital, segue a lógica de financiamento por fórmulas (VELLOSO, 2000), isto é, o bolo orçamentário é repartido entre as diferentes instituições a partir de uma matriz.

Denominada Matriz Andifes ou Matriz OCC (Outros Custeios e Capital), seu nome deriva do fato de que sua elaboração resultou de uma ação conjunta entre o Ministério da Educação e a Associação de Dirigentes de Instituições Federais de Ensino Superior (Andifes), conferida pelo Decreto 7.233/2010 (BRASIL, 2010a). O referido decreto já sinalizava, em seu artigo $4^{\circ}$, parágrafo $2^{\circ}$, os parâmetros a serem considerados na composição da fórmula e que orientariam a distribuição dos recursos orçamentários. Seriam eles:

I - o número de matrículas e a quantidade de alunos ingressantes e concluintes na graduação e na pós-graduação em cada período; II - a oferta de cursos de graduação e pós-graduação em diferentes áreas do conhecimento; III - a produção institucionalizada de conhecimento científico, tecnológico, cultural e artístico, reconhecida nacional ou internacionalmente; IV - o número de registro e comercialização de patentes; $\mathrm{V}$ - a relação entre o número de alunos e o número de docentes na graduação e na pós-graduação; VI - os resultados da avaliação pelo Sistema Nacional de Avaliação da Educação Superior - SINAES, instituído pela Lei no 10.861, de 14 de abril de 2004; VII - a existência de programas de mestrado e doutorado, bem como respectivos resultados da avaliação pela Fundação Coordenação de Aperfeiçoamento de Pessoal de Nível Superior - CAPES; e VIII - a existência de programas institucionalizados de extensão, com indicadores de monitoramento (BRASIL, 2010a).

Tais parâmetros não foram totalmente materializados na Matriz OCC, tal como se pode perceber na Portaria MEC 651/2013 (BRASIL; MEC, 2013), que define seus contornos vigentes. Aspectos como o registro de patentes ou a institucionalização de programas de extensão foram ignorados, enquanto outros relativos à produção de conhecimento, à avaliação dos cursos pelo Sinaes e à pós-graduação pela Capes são a tal ponto sub-representados que não são determinantes na repartição orçamentária. O resultado foi uma matriz reduzida, menos sensível à diversidade de finalidades do ensino superior e da diversidade de ações que marcam sua existência. De forma descritiva, a matriz toma como parâmetros os indicadores de: a) estudantes diplomados ; b) estudantes ingressantes; c) duração padrão dos cursos (tempo mínimo de integralização dos créditos estabelecido no Projeto Pedagógico do Curso); d) peso do grupo dos cursos (constante estabelecida pela ANDIFES atribuindo pesos diversos aos cursos); e) fator de Retenção (constante estabelecida pela ANDIFES atribuindo aos cursos pesos de retenção) ; f) bônus fora de Sede (bônus atribuídos para cursos em instituições alocadas em município fora da sede); e g) bônus por turno noturno (bônus atribuídos para cursos cujas atividades ocorram em turnos noturnos).

Isto posto, parece claro que o financiamento da educação superior federal no Brasil, especialmente para custeio e capital, depende de condições estruturais e institucionais pouco variáveis, por um lado, e dos resultados de diplomação da universidade, por outro. Se se levar em consideração que as universidades replicam, com graus variáveis de fidelidade, a Matriz OCC para suas matrizes locais, estabelecendo mecanismos de rateio orçamentário entre unidades acadêmicas, poder-se-ia intuir que a

\footnotetext{
${ }^{3}$ Tanto os recursos advindos da prestação de serviços quanto aqueles provenientes de contratos firmados com as IFES não são resultantes de uma matriz cuja variável de destaque é o volume da evasão, tal como ocorre com os recursos do Tesouro. Educação em Revista|Belo Horizonte|v.37|e26524|2021
} 
diplomação é igualmente importante para a alocação de recursos para cada curso, determinando sua capacidade de se reproduzir e crescer.

Espelhando a Matriz OCC, foi desenvolvida também a Matriz Programa Nacional de Assistência Estudantil (PNAES), fórmula responsável pela repartição do bolo orçamentário do PNAES entre as várias IFES. A única variável que destoa da origem das demais é o Índice de Desenvolvimento Humano do Município (IDHM) em que o curso está localizado (MACHADO, 2017; MARTINS; ARAÚJO JÚNIOR; RODRIGUES, 2019). Note-se que não há nenhum indicador específico de condição de vulnerabilidade socioeconômica de estudantes para orientar a alocação orçamentária do programa de assistência estudantil. Isto decorre do fato de se ter aproveitado uma matriz de financiamento cuja intenção era imprimir uma lógica orçamentária indutora dos resultados acadêmicos esperados.

No entanto, a assistência estudantil requer financiamento para combater as desigualdades sociais que interferem no acesso ao direito à educação. Portanto, a Matriz PNAES não deveria replicar conteúdo da Matriz OCC, por se tratar de mecanismos de alocação com objetivos muito distintos. Mesmo que se devote qualquer destaque ao IDHM, deve-se reconhecer que este indicador registra condições de renda, longevidade e educação do município, igualando os munícipes, ignorando origens sociais e regionais, além de desconsiderar as características de nosso sistema de educação superior, especialmente com a criação e implementação do Sistema de Seleção Unificada (SiSU).

Portanto, deve-se concluir, da forma como se fez para a Matriz OCC, que também a Matriz PNAES é sensível às condições estruturais e institucionais das IFES razoavelmente fixas, bem como dos quantitativos de estudantes diplomados ou evadidos, reconhecendo-se ainda a influência do IDHM do município em que se encontra o curso. Não seria demais reforçar, portanto, que a evasão é peça chave para determinar a alocação de recursos de custeio e capital entre IFES e entre suas unidades acadêmicas internas, bem como para seu programa de assistência estudantil. Destarte, evidencia-se que o volume de estudantes evadidos tem participação relevante na definição dos orçamentos das IFES e dos seus programas de assistência estudantil, sinalizando claramente um estímulo governamental à ampliação dos índices de diplomação.

\section{A DEFINIÇÃO DE EVASÃO PARA O INEP/MEC}

A bibliografia tem sido repetitiva ao utilizar os estudos de Vicent Tinto como fundadores do campo científico que trata da evasão na educação superior. Aproveitando-se da introdução de seu Dropout from higher education: A theoretical synthesis of recent research, de 1975, vale a pena recordar que entre os motivadores do texto estava a constatação de que a produção teórica, até aquela data, era acompanhada de duas deficiências: a inadequada atenção dada à definição e a ausência de um modelo teórico longitudinal. Dizia Tinto, acerca da primeira deficiência, ser muito comum encontrar trabalhos que não diferenciavam os "fracassos acadêmicos" dos abandonos voluntários, ou as evasões definitivas daquelas temporárias; por fim, nem mesmo discriminavam do abandono as transferências entre instituições (TINTO, 1975, p. 89-90). O resultado da indiferenciação iludia pesquisadores ao encaminhá-los para achados contraditórios e incapacitava o gestor público ao levá-lo a sobrestimar a extensão do fenômeno, a não lhe permitir definir adequadamente o público-alvo e a torná-lo inapto para formular a devida política pública de enfrentamento. Mais do que descrever ocorrências de abandonos, ou associá-las a "fracassos acadêmicos" e condições sociais, Tinto desejava construir um modelo longitudinal capaz de separar o que deve e o que não deve ser chamado de evasão, bem como explicar como os fatores intervenientes produzem seus efeitos.

O debate acadêmico acerca do tema tem produzido artigos, dissertações e teses que dão à evasão razoável importância. De forma geral,

No Brasil existe uma significativa diversidade de concepções de evasão. Para efeitos didáticos, e com o intuito de simplificar a análise das várias acepções existentes de evasão, é possível agrupar os vários conceitos como derivados de três grandes matrizes, que podem ser assim resumidas: a) as que derivam do conceito de evasão elaborado pela Comissão Especial constituída pelo MEC, que analisa a evasão a partir de três dimensões (evasão do curso, da instituição e do sistema); b) as que derivam da teoria e do conceito estabelecidos por Tinto (1975), que partem da análise da trajetória do discente para verificar a evasão; c) as que vislumbram a evasão,

Educação em Revista|Belo Horizonte|v.37|e26524|2021 
enquanto problema público, apenas quando existirem fatores excludentes que independam da vontade do discente, e que impliquem em total saída do discente do ensino superior, desconsiderando a mobilidade, por exemplo, como evasão, como bem especifica Ristoff (1999) (SILVA et al., 2019).

Por seu turno, para o universo institucional, administrativo, composto pela rotina dos policy makers $^{4}$, a evasão também tem sido uma categoria administrativa muito presente - cara, sobretudo, às atenções do Ministério da Educação e seus órgãos de pesquisa (INEP - Instituto Nacional de Estudos e Pesquisas Educacionais Anísio Teixeira), dos quais parte a compreensão oficial do fenômeno. De um documento de 2017, intitulado Metodologia de Cálculo dos Indicadores de Fluxo da Educação Superior (INEP, 2017), pode-se extrair a definição que interessa a este estudo. A bem da verdade, assim como reconhecem seus autores, a definição que se verá adiante tem origem nas análises do governo federal sobre a educação básica, adaptadas para a educação superior (INEP, 2017, p. 11). Entende o INEP que a evasão é a

saída antecipada, antes da conclusão do ano, série ou ciclo, por desistência (independentemente do motivo), representando, portanto, condição terminativa de insucesso em relação ao objetivo de promover o aluno a uma condição superior a de ingresso, no que diz respeito à ampliação do conhecimento, ao desenvolvimento cognitivo, de habilidades e de competências almejadas para o respectivo nível de ensino. Obviamente, a interrupção do programa em decorrência de falecimento do discente não pode ser atribuída como insucesso, dado que, de forma geral, se trata de caso fortuito e não se pode presumir uma intencionalidade do indivíduo em interromper o curso, cessá-lo ou uma incapacidade do indivíduo de manter-se no programa educacional (INEP, 2017, grifos meus).

O trecho acima é rico em detalhes e exige uma leitura pormenorizada. Há quatro aspectos importantes a serem analisados: a independência em relação aos motivos, a condição terminativa, a condição de insucesso e a exclusão dos casos de falecimento. Antes de tudo, a evasão é aqui definida como uma saída antecipada, indicando a compreensão de que haveria um tempo adequado para esta, coincidente com a diplomação. Tal saída é registrada independente do motivo, ou seja, sem que haja qualquer atenção para a causação que a produz. Isto quer dizer que, aos olhos do INEP e do MEC, as razões da perda de vínculo não são importantes para caracterizar o fenômeno, pois, quaisquer que sejam as causas, a interpretação se limitará a compreendê-lo como uma simples perda de vínculo.

Ora, a opção pelo recorte suscita uma problematização necessária. A realidade social a qual se deseja informar é a perda do vínculo com o sistema de ensino superior; todavia, a desconsideração das razões permite tornar idênticas situações imiscíveis. Para ilustrar a ponderação, pode-se tomar como referência o estudo realizado pelo próprio MEC e pela ANDIFES em 1996 sobre a evasão, quando se constituiu a Comissão Especial de Estudos sobre a Evasão nas Universidades Públicas Brasileiras (SESU/MEC; ANDIFES; ABRUEM, 1996). Sem realizar pesquisa de campo, o estudo apresenta como hipotéticas razões para a evasão mais de 40 situações distintas, agregadas em três grandes grupos: a) fatores referentes a características individuais do estudante; b) fatores internos às instituições; e c) fatores externos às instituições.

Os primeiros são relativos às

habilidades de estudo; relacionados à personalidade; decorrentes da formação escolar anterior; vinculados à escolha precoce da profissão; relacionados a dificuldades pessoais de adaptação à vida universitária; decorrentes da incompatibilidade entre a vida acadêmica e as exigências do mundo do trabalho; decorrentes do desencanto ou da desmotivação dos alunos com cursos escolhidos em segunda ou terceira opção; decorrentes de dificuldades na relação ensinoaprendizagem, traduzidas em reprovações constantes ou na baixa freqüência às aulas; decorrentes da desinformação a respeito da natureza dos cursos; decorrente da descoberta de novos interesses que levam à realização de novo vestibular (SESU/MEC; ANDIFES; ABRUEM, 1996).

Por seu turno, aqueles fatores internos às instituições são

\footnotetext{
${ }^{4}$ Expressão em língua inglesa normalmente utilizada para se referir a formuladores(as) e gestores(as) de políticas públicas.
} Educação em Revista|Belo Horizonte|v.37|e26524|2021 
peculiares a questões acadêmicas; currículos desatualizados, alongados; rígida cadeia de prérequisitos, além da falta de clareza sobre o próprio projeto pedagógico do curso; relacionados a questões didático-pedagógicas: por exemplo, critérios impróprios de avaliação do desempenho discente; relacionados à falta de formação pedagógica ou ao desinteresse do docente; vinculados à ausência ou ao pequeno número de programas institucionais para o estudante, como Iniciação Científica, Monitoria, programas PET (Programa Especial de Treinamento), etc.; decorrentes da cultura institucional de desvalorização da docência na graduação; decorrentes de insuficiente estrutura de apoio ao ensino de graduação: laboratórios de ensino, equipamentos de informática, etc.; inexistência de um sistema público nacional que viabilize a racionalização da utilização das vagas, afastando a possibilidade da matrícula em duas universidades (SESU/MEC; ANDIFES; ABRUEM, 1996).

E, por fim, os fatores externos às instituições compreendem aqueles aspectos

relativos ao mercado de trabalho; relacionados ao reconhecimento social da carreira escolhida; afetos à qualidade da escola de primeiro e no segundo grau; vinculados a conjunturas econômicas específicas; relacionados à desvalorização da profissão, por exemplo, o "caso" das Licenciaturas; vinculados a dificuldades financeiras do estudante; relacionados às dificuldades de atualizar-se a universidade frente aos avanços tecnológicos, econômicos e sociais da contemporaneidade; relacionados a ausência de políticas governamentais consistentes e continuadas, voltadas ao ensino de graduação (SESU/MEC; ANDIFES; ABRUEM, 1996).

Sem desejar promover uma análise sobre o grau de acerto da tipologia ou da agregação dos casos em cada modalidade, parece muito fértil recolher o reconhecimento da referida Comissão para a diversidade de causações. Também é razoável pensar que situações distintas podem encaminhar diagnósticos igualmente distintos, levando a gestão pública a produzir políticas públicas específicas. Na indiferenciação dos casos, não restam aos policy makers muitas alternativas. Com efeito, a opção do INEP em definir a evasão "independentemente do motivo" produz um diagnóstico inconclusivo sobre o fenômeno e impede a ação pública assertiva, precisa, eficaz e eficiente.

Por outro lado, e seguramente mais importante, ao discriminar os casos conforme três tipos, a Comissão deixa claro que dois deles são fatores externos às instituições ou de natureza individual. A externalidade que encaminha à perda de vínculo não permite associar a evasão a fracassos das IES. Desse modo, respeitados os motivos, as conexões causais do fenômeno da evasão são levadas para a amplidão das relações pessoais, institucionais e sociais, evidenciando a complexidade deste objeto. Trata-se, pois, de incorreta simplificação a associação exclusiva dela à dimensão institucional, sobretudo porque não se sabe a participação ou o peso de cada grupo de fatores na determinação do volume de estudantes evadidos(as).

Portanto, a invisibilidade das razões para evadir deixa sem luz o fenômeno e sem ação a agência pública. Aquilo que a categoria administrativa "evasão" comunica, tal como definida pelo INEP, não guarda serventia para indicar um problema público, pois não permite saber, antes de tudo, se ao menos o é e de quem é tal problema. Com efeito, quando um problema social se transforma em um problema público (SECCHI, 2016), a agência pública mobiliza seus esforços para apontar uma solução. É nítido que a evasão tem sido abordada como um problema, todavia cabe questionar se todas as razões possíveis para ela existir a encaminham para esta condição.

Assim, caminha-se para uma situação insolúvel, qual seja: optou-se por ignorar as motivações da evasão e, ao mesmo tempo, requerem-se do MEC ações para o enfrentamento sem que lhe seja dado ciência do que atacar. Impossível saber se caberiam reforços da assistência estudantil ou da revisão curricular; se os volumes encontrados em cursos de Educação à distância de instituições privadas podem ser tratados igualmente aos casos dos cursos presenciais em instituições federais; ou, ainda, se as ações são da alçada desta pasta ministerial ou de outra, para casos que envolvem, por exemplo, a baixa atratividade da carreira profissional ou problemas do mercado de trabalho.

Um segundo aspecto a ser destacado na definição diz respeito à indicação de sua condição terminativa. A saída antecipada, antes da conclusão, é entendida como o encerramento definitivo do vínculo com o curso, com a instituição ou com o sistema superior de ensino. Soa como uma morte acadêmica. Por um lado, este parece ser um vício de origem, redundante da importação das categorias 
aplicadas à educação básica. Por outro, é compreensível a opção do INEP em atribuir esta natureza ao fenômeno, afinal, se a condição de desligamento fosse reconhecida como possivelmente transitória, a mensuração da evasão dependeria do acompanhamento do fluxo de ingresso e de egresso nos cursos e instituições durante determinada série histórica ou durante toda a história. Se isso fosse feito, o fluxo traria a necessidade de reconhecer como desvinculada somente a pessoa que jamais houvesse reingressado ao sistema superior de ensino, exigindo que se utilizassem indicadores de evasão bruta e líquida (descontados os reingressos). Dessa forma, tratá-la como um fenômeno terminativo facilita a mensuração.

De início, seria importante, ao menos, trazer à baila as considerações do já citado estudo da Comissão Especial de Estudos sobre a Evasão nas Universidades Públicas Brasileiras. Ali se pode ler que existe a expectativa por parte dos(as) elaboradores(as) do relatório de que discentes evadidos(as) retornem ao ensino superior, sobretudo para os casos em que predominam fatores referentes a características individuais do estudante (SESU/MEC; ANDIFES; ABRUEM, 1996). Advoga o texto que estudantes ingressantes com pouca idade, ainda sem grande certeza sobre a carreira profissional a seguir e pouco conhecimento sobre o curso em que ingressaram, tendem a promover a troca assim que mais claras fiquem suas intenções e noções. Destarte, a evasão e o reingresso são ali tomados como componentes esperados no processo de amadurecimento estudantil, e não um processo terminativo, irrevogável e identificado ao fracasso.

Esta impressão é reforçada pela própria arquitetura vigente até 2018 do Sistema de Seleção Unificada (SISU). Antes da recente alteração, o sistema responsável pelo ingresso de importante fração de discentes na rede pública de ensino superior permitia a opção por dois cursos, sendo que a aprovação na segunda opção poderia ser feita enquanto se aguardava a definição da vaga na lista de espera da primeira opção. Assim que a vaga de primeira opção fosse garantida, o(a) estudante faria a migração do curso de segunda opção. Esta possibilidade foi responsável por garantir intensa mobilidade entre cursos, respeitando-se a vontade prioritária do(a) candidato(a) à vaga. Sem elaborar juízo acerca da decisão do MEC em alterar este procedimento, o fato inconteste é que a mobilidade entre cursos, evasão e reingresso eram partes constitutivas da rotina de seleção de vagas via SISU. Logo, a evasão não seria condição terminativa pelo que estabelecia o principal mecanismo de acesso ao ensino superior do País.

Além de a própria mecânica do ingresso no ensino superior possibilitar mobilidades (contabilizadas como evasões), a realidade nas IES também parece indicar que evasões são, comumente, sucedidas por reingressos às vezes imediatos, às vezes postergados. Esta é a base que sustenta o texto de Lima Junior et al. (2019). O artigo faz fértil crítica à validade dos indicadores de Taxa de Sucesso da Graduação (TSG) e de Taxa de Conclusão da Graduação (TCG) - a primeira utilizada pelo Tribunal de Contas da União (TCU), e a segunda, criada pelo REUNI (BRASIL, 2007a). As fragilidades apontadas podem ser lidas a seguir:

Outro problema presente no cálculo da TSG e da TCG diz respeito à forma como os estudantes
são contados: usualmente são consideradas vagas, ingressos e matrí́culas, mas não os indivíduos
propriamente ditos. Com a expansão e a diversificação da educação superior, é cada vez mais
comum que alunos façam novo ingresso para mudar de curso ou de instituiçãa. Cada vez mais,
a evasão do curso não é evasão propriamente dita, mas mobilidade. Uma forma de dar conta das
trajetórias cada vez mais complexas realizadas pelos alunos é acompanhá-los pelo número de seu
cadastro de pessoa física (CPF), em uma abordagem longitudinal (LIMA JUNIOR et al., 2019,
p. 165).

Esta constatação acerca da forte presença da mobilidade entre os(as) chamados(as) evadidos(as) pode ser reforçada ao se observar o rol de achados da dissertação de mestrado de Viana (2020). A autora estudou o fluxo dos(as) estudantes cotistas evadidos(as) no ano de 2010, de acordo com o Censo da Educação Superior. Descobriu 1.315 casos nesta condição; destes, 289 (21,97\%) não regressaram a nenhuma instituição de ensino superior até 2016 . Todavia, 1.026 (78,02\%) reingressaram, sendo que, do total evadido (1.315), 227 (17,26\%) evadiram novamente, 317 (24,10\%) estavam cursando e $482(36,61 \%)$ regressaram e se já formaram. Este estudo induz à conclusão de que a maior parte deste seleto público de estudantes tem a evasão como um adiamento ou uma suspensão temporária do vínculo, e não uma condição terminativa de perda dessa vinculação. Cabe ainda, para confirmar o que se percebeu 
para amostra tão pequena, um estudo longitudinal que abarque o fluxo (evasão e reingresso) em todo o ensino superior brasileiro.

Antes de avançar sobre novo tópico da definição de evasão do documento em análise, merece destaque outro aspecto da citação recuada acima. Chama atenção o fato de que o INEP contabiliza a evasão, em geral, e a perda de vínculo, em específico, a partir do registro das vagas, e não dos indivíduos. Quando são contabilizadas as matrículas trancadas, por exemplo, não se quantifica o número de estudantes que as trancou, mas efetivamente quantas vagas em cursos tiveram sua condição suspensa. Desse modo, a título de ilustração, um(a) estudante matriculado(a) em três cursos ao mesmo tempo (dois à distância e um presencial), pode trancar dois à distância e manter-se cursando uma faculdade presencialmente. Ao fim do ano, o INEP contabilizará duas matrículas trancadas, ainda que seja um único CPF autor de ambas.

A obviedade deve ser problematizada, pois o mesmo se dá com a evasão. Quando o INEP anuncia a evasão absoluta, relativa e sua taxa, ele está indicando a quantidade de vagas cujo vínculo com um(a) estudante foi perdido, e não a quantidade de estudantes evadidos(as). Esta constatação instigou Lima Junior et al. (2019) a proporem novos indicadores de avaliação para o ensino superior.

Retomando a problematização da condição terminativa da evasão na definição do INEP e valendo-se dos microdados do Censo da Educação Superior, em 2010 (INEP, 2011), havia 8.337.219 matrículas em IES brasileiras - destas, 1.138 .298 (13,65\%) registradas na situação acadêmica de "desvinculados do curso". Além dessa caracterização, o INEP também utiliza as condições "cursando", "matrícula trancada", "transferência para outro curso da mesma IES", "formado" e "falecido". Assim, sob a rubrica de "desvinculados do curso" estão abandonos das mais diversas naturezas, tais como desistências, expulsões, jubilamentos, transferência para outras IES etc.

Quando discriminados pela categoria administrativa da IES, os(as) desvinculados(as) do curso representavam 15,08\% entre estudantes de instituições privadas sem fins lucrativos; 13,85\% para privadas com fins lucrativos; $12,46 \%$ para públicas municipais; $11,76 \%$ para públicas federais; e $8,79 \%$ para públicas estaduais. Quanto ao grau acadêmico, na licenciatura representavam 13,64\% contra 12,89\% para bacharelado. Acerca da modalidade, para cursos à distância compunham 16,01\% contra 13,35\% para cursos presenciais. Já entre estudantes do sexo masculino, os desvinculados eram $14,88 \%$, percentual superior ao mesmo quadro para o sexo feminino (12,68\%). Para o critério racial, a diferença não suplantava um ponto percentual, mas quando se leva o olhar para a modalidade de ingresso, entre cotistas, os(as) desvinculados(as) eram 7,07\% e, entre não cotistas, somavam 13,76\%. Entre cobertos(as) pela assistência estudantil, os(as) desvinculados(as) correspondiam a 10,55\%, enquanto os(as) sem cobertura chegavam a 13,88\%. Observando o fenômeno entre aqueles(as) que participavam de atividades acadêmicas (iniciação científica, monitoria, extensão etc.), o volume chegava ao patamar de 6,60\%; já entre aqueles(as) que não participavam, a cifra subia para 14,56\%. No que se refere ao turno, os valores eram maiores entre estudantes do noturno (14,20\%), seguidos dos estudantes do matutino (12,5\%), vespertino $(11,04 \%)$ e integral $(10,03 \%)$. Por fim, quando observada a faixa etária, os(as) desvinculados(as) representavam 15,2\% entre estudantes de 25 anos ou mais e 12,08\% entre estudantes de 18 a 24 anos.

Para constatar a natureza terminativa da evasão, seria importante observar que o volume de estudantes que perdeu o vínculo não mais retornou ao sistema de ensino superior. Todavia, parte do volume desvinculado em 2010 estava constando como discente matriculado nos anos posteriores. A título de ilustração, 53,96\% dos discentes registrados como "desvinculado do curso" em 2010 estavam matriculados em 2012 (INEP, 2013), dois anos depois. Nem todos foram registrados como reingressantes, pois alguns sequer saíram do sistema. O que parece estranho, na verdade, resulta da forma como se contabiliza a evasão: pela vaga, e não por estudante. Já se sabe que havia 8.337.219 matrículas em 2010, mas somente 7.610.696 discentes, sendo 6.938 .739 (91,17\%) com uma matrícula e 671.957 $(8,83 \%)$ com mais de uma matrícula (de duas a nove).

Deste modo, um(a) estudante com mais de uma matrícula pode ter sido contabilizado(a) como evadido(a) (condição terminativa), quando somente encerrou um dos seus vínculos, mantendo os demais. Neste momento, cabe ponderar que, se uma das finalidades da educação superior é a diplomação, a perda de um de vários vínculos com o sistema não deveria ser tratada como um problema em si, uma vez que a conclusão pode se dar no curso em que a matrícula foi mantida - ou, por outro lado, também 
não poderia ser considerada como uma perda de vínculo semelhante àquela de quem possui um único e exclusivo vínculo.

Seguindo o mesmo raciocínio, vale dizer que, se em 2012 ainda se encontravam vinculados os(as) chamados(as) evadidos(as) do ano de 2010 em 53,96\%, em 2017 (INEP, 2018) este valor era de 28,21\%. Assim, um em cada quatro classificados como evadidos em 2010 não estava desvinculado do sistema de educação superior sete anos depois. Desse modo, a chamada evasão não é terminativa para uma boa parte dos(as) estudantes que se desvinculam das IES, e estes(as) fazem do reingresso ou da redução de múltiplos vínculos uma etapa usual da trajetória acadêmica.

A Tabela 1 indica que estudantes desvinculados(as) em 2010 e que estiveram na condição de vinculados(as) em 2012 estão em sua maioria na situação "cursando", seguida das situações "desvinculado do curso", "matrícula trancada", "formado", "transferência para outro curso da mesma IES" e "falecido". Note-se que o perfil da situação acadêmica dos(as) estudantes em reingresso é muito semelhante aos seus pares, isto é, se compararmos a composição percentual expressa na Tabela 1, encontraremos números semelhantes aos que expressam a situação acadêmica da totalidade dos(as) estudantes das IES nos censos respectivos. A título de ilustração, no ano de 2012, do total de estudantes das IES do Brasil, 62,7\% estavam cursando; 10,2\% constavam com matrícula trancada; $15,1 \%$ estavam desvinculados do curso; $1,0 \%$ como transferido para outro curso da mesma IES; $11,0 \%$ como formado; e $0,0 \%$ em falecido (INEP, 2013).

Tabela 1 - Situação Acadêmica em 2012 de estudantes desvinculados(as) em 2010

\begin{tabular}{lc}
\hline SITUAÇÃO ACADÊMICA & $\mathbf{2 0 1 2}$ \\
\hline Cursando & $59,2 \%$ \\
Matrícula trancada & $11,2 \%$ \\
Desvinculado do curso & $20,0 \%$ \\
Transferência para outro curso da mesma IES & $1,2 \%$ \\
Formado & $8,3 \%$ \\
Falecido & $0,0 \%$ \\
Total & $100,0 \%$ \\
\hline
\end{tabular}

Fonte: Censo da Educação Superior (INEP). Elaboração própria.

De qualquer forma, já se pode apontar que a realidade do ensino superior brasileiro é permeada pela perda de vínculo sem que isto signifique necessariamente uma condição terminativa. Caberá aos órgãos oficiais promoverem a adaptação de seus mecanismos de diagnóstico para que sejam capazes de ler a realidade como ela é, isto é, percebendo o fluxo como parte inerente ao processo de formação no ensino superior. Enquanto for mantida a atual definição, ela estará condenada a produzir um retrato enviesado, um simulacro da evasão, uma imagem construída de um fenômeno estranho à realidade. As constatações devem devolver nossa atenção para a forma como o INEP contabiliza a evasão e a identifica com insucesso, instigando diagnósticos, avaliações e políticas públicas. Reduzindose a observar a perda de vínculo bruta (sem descontar os reingressos ou múltiplos vínculos) e estática (restrita aos contornos de um ano), perde-se sua dimensão líquida e dinâmica (observando-se as trajetórias).

Retomando a sequência de aspectos suscitados pela definição de evasão no documento do INEP, pode-se agora dedicar alguma atenção ao terceiro. Quando o texto indica a condição terminativa da evasão, ele não a faz no vazio, mas, sim, como representação do insucesso no objetivo de alcançar patamar superior (de conhecimento, capacidade cognitiva, competências e habilidades) em relação ao nível de ingresso (INEP, 2017). Aqui, duas ponderações merecem reflexão.

Primeiramente, a compreensão da evasão como fracasso ou insucesso - extremamente comum na bibliografia especializada (BAGGI; LOPES, 2011) - é construída com o intuito de produzir uma avaliação, uma aferição de resultados, sobre o ensino superior. Deve-se ter claro que, a rigor, considerar a evasão como mecanismo avaliativo exige que isso se faça dentro de um exercício geral de avaliação institucional (RISTOFF, 1999), pensando-se sua relação com as várias dimensões expressas da atividade educacional para este nível de ensino. Entretanto, uma vez que o levantamento da situação de perda de vínculo é feito sem a percepção da motivação, torna-se impossível avaliar se a saída representa 
ou não um fracasso. E, caso fosse utilizada e evidenciasse insucesso, a motivação também permitiria atribui-lo ao(à) estudante, ao curso, à instituição, ao Ministério da Educação ou à sociedade. Como não é percebida, tal atribuição não pode ser realizada.

Segundamente, a noção de insucesso presume ser capaz de avaliar como nulo o nível de cumulação de conhecimento, capacidade cognitiva, competências e habilidades de um(a) discente evadido(a). Levando às últimas consequências as expectativas que a própria definição joga sobre si, ela compreenderia como integralmente bem-sucedido um caso de diplomação, assim como interpretaria como indiferentemente malsucedidas as evasões no primeiro ou no último período do curso. Por um lado, não se deve concluir que o acesso ao diploma tenha conferido a cumulação desejada, assim como não se pode presumir, sem avaliação mais criteriosa, que a saída antecipada não tenha permitido cumprir as finalidades propostas. A definição presente no documento do INEP eleva à condição de critério absoluto de atribuição de sucesso a diplomação do(a) discente.

Se forem observados os resultados extraídos da aplicação dos Exames Nacionais do Ensino Superior (ENADE), pode-se perceber que a construção dos indicadores avaliativos contempla a cumulação de conhecimento durante o período formativo. Este é o caso do Indicador de Diferença dentre os Desempenhos Observado e Esperado (IDD). O IDD "é um indicador de qualidade que busca mensurar o valor agregado pelo curso ao desenvolvimento dos estudantes concluintes" (INEP, 2019). O IDD muito baixo de alguns(algumas) estudantes deve indicar que a conclusão do curso não possibilitou agregação substantiva de capital cultural durante a passagem pela educação superior. Ora, a combinação da presença do IDD e a possibilidade de aferição de resultados baixos é a prova de que a diplomação não pode ser tomada como um critério absoluto de sucesso.

$\mathrm{Na}$ outra ponta, como não se aplica o ENADE de forma seriada, mas somente no fim do curso, não se poderia mensurar o valor agregado durante cada etapa do processo formativo. Assim sendo, e valendo-se do IDD como único mensurador nacional de cumulação de capital cultural para o ensino superior, em todos os casos de antecipação da saída antes da diplomação não seria possível afirmar que esta implica absoluto insucesso.

Aliás, aqui se deve chamar a atenção para a ausência de vínculo mais estreito entre a noção de insucesso (e sucesso) presente na definição da evasão do INEP e as finalidades da educação superior estabelecidas pela LDB (BRASIL, 1996). A lei é clara ao indicar como finalidades:

I - estimular a criação cultural e o desenvolvimento do espírito científico e do pensamento reflexivo; II - formar diplomados nas diferentes áreas de conhecimento, aptos para a inserção em setores profissionais e para a participação no desenvolvimento da sociedade brasileira, e colaborar na sua formação contínua; III - incentivar o trabalho de pesquisa e investigação científica, visando o desenvolvimento da ciência e da tecnologia e da criação e difusão da cultura, e, desse modo, desenvolver o entendimento do homem e do meio em que vive; IV - promover a divulgação de conhecimentos culturais, científicos e técnicos que constituem patrimônio da humanidade e comunicar o saber através do ensino, de publicações ou de outras formas de comunicação; V - suscitar o desejo permanente de aperfeiçoamento cultural e profissional e possibilitar a correspondente concretização, integrando os conhecimentos que vão sendo adquiridos numa estrutura intelectual sistematizadora do conhecimento de cada geração; VI estimular o conhecimento dos problemas do mundo presente, em particular os nacionais e regionais, prestar serviços especializados à comunidade e estabelecer com esta uma relação de reciprocidade; VII - promover a extensão, aberta à participação da população, visando à difusão das conquistas e benefícios resultantes da criação cultural e da pesquisa científica e tecnológica geradas na instituição. VIII - atuar em favor da universalização e do aprimoramento da educação básica, mediante a formação e a capacitação de profissionais, a realização de pesquisas pedagógicas e o desenvolvimento de atividades de extensão que aproximem os dois níveis escolares (BRASIL, 1996).

Desse modo, as noções de sucesso ou fracasso, entendidas como as mensurações de resultados positivos e negativos, deveriam ser observadas à luz do que se compreende como finalidades da educação superior. A Lei 9.394/96 não elenca as finalidades do ensino superior de forma hierárquica ou condicionada, levando-se a crer que o interesse do(a) legislador(a) foi conferir igualdade a elas. Sendo isso verdade, merece destaque o fato de que, das oito finalidades, somente uma diz respeito estritamente à diplomação para o trabalho, a segunda. Em todas as demais, é possível que o(a) estudante as desenvolva 
durante seu curso de forma plena ou quase plena sem, necessariamente, obter seu diploma. Isso não se deve ao fato de a LDB ser negligente quanto à diplomação, afinal, cada projeto pedagógico de curso busca materializar a cumulação de habilidades e competências nos créditos distribuídos ao longo da grade curricular. Todavia, a LDB parece não reduzir a atividade universitária à fabricação de diplomados ou à formação de força de trabalho. Nesse sentido, a referida lei segue fiel ao conteúdo constitucional quando a carta magna assevera em seu artigo 205 que a educação visa "ao pleno desenvolvimento da pessoa, seu preparo para o exercício da cidadania e sua qualificação para o trabalho" (BRASIL, 1988). Transparece, portanto, que seria reducionista identificar a plenitude do preparo da pessoa, de sua cidadania e suas capacidades para o trabalho à aquisição do diploma.

Isso posto, percebe-se que o conteúdo da referida lei (LDB) atribui à universidade um papel destacado no processo civilizatório, na direção de uma sociedade mais justa, democrática, desenvolvida e plural. A avaliação do sucesso ou fracasso universitário deveria, rigorosamente, levar em consideração a totalidade das finalidades, sem a redução à dimensão do mercado de trabalho ou da conclusão de créditos de ensino. Da mesma maneira, quaisquer outros fenômenos universitários, tal como a evasão, deveriam ser submetidos aos juízos levando-se em consideração a gama de fins a que o sistema se destina. Isto exigiria que se considerasse a perda de vínculo com o ensino superior como um problema em situações específicas, dependendo das causas e do cumprimento ou não das finalidades da educação superior.

Para tanto, as avaliações de sucesso ou fracasso acadêmico deveriam antes se debruçar sobre formas de se perceber a participação do(a) discente no processo de criação cultural, de desenvolvimento do espírito científico, do pensamento reflexivo, do entendimento do ser humano e seu meio, de divulgação do conhecimento com desejo de aperfeiçoá-lo, bem como de ampliá-los sobre os problemas nacionais e desenvolver serviços à comunidade, estendendo conquistas e benefícios, bem como contribuir com o aperfeiçoamento da educação básica.

Levando-se ao cabo a recomendação, dever-se-ia perguntar: qual o percentual do corpo discente que participou, durante seu percurso acadêmico, de programas de iniciação científica e extensão universitária? Qual o tamanho da fração do mesmo corpo que se interessou pelos problemas nacionais, refletiu sobre a temática, produziu algum conhecimento e o pôs em diálogo com a comunidade? Quem criou e difundiu cultura? Quem participou de processo de melhoria da educação básica brasileira?

Note-se que nenhuma dessas perguntas podem ser respondidas se se tem acesso somente ao quantitativo de diplomações, reprovações, retenções e evasões, como se habitualmente faz. Requer-se, por conseguinte, um processo avaliativo capaz de capturar os aspectos olvidados das finalidades da educação.

Por fim, o último aspecto da definição em análise a se problematizar diz respeito à exclusão do cômputo dos casos de falecimento do universo dos(as) evadidos(as). Desse modo, além dos casos de transferência interna (dentro de uma mesma Instituição de Ensino Superior), também os falecimentos não serão reconhecidos como casos de evasões. Tal reconhecimento se deve ao fato de o INEP tratá-lo como caso fortuito, representando uma saída do curso sem intencionalidade, ou que não revela a incapacidade do indivíduo de manter-se no programa educacional (INEP, 2017).

Ao que tudo indica, a definição mergulhou num paradoxo em termos. Como se sabe, propositalmente o INEP declinou da possibilidade de investigar a motivação, e este fato impeliu este trabalho a acusar que tal escolha anula a possibilidade de se observar a evasão como um problema. Entretanto, recorre a um argumento motivacional para excluir os falecimentos da contabilidade da evasão. Quando se apela ao juízo sobre a natureza fortuita, não planejada ou desvinculada da intenção, o INEP está indicando não ter condições de associar o insucesso ao falecimento, situação que exige ignorar seu cômputo. Ora, mas é justamente este o ponto. Quando não se pode fazer tal exercício sobre todos os casos de perda de vínculo, não se pode afirmar que a falha, o fracasso, sequer existe.

Se do ponto de vista semântico se pode perceber o paradoxo, do ponto de vista empírico ele fica ainda mais evidente. Afinal, seriam vários os casos de evasão (diferentes do falecimento) que também não poderiam ser percebidos como não intencionais, fortuitos e não preditivos da incapacidade do(a) estudante. Condições sociais, familiares, físicas, entre outras, poderiam levar à perda de vínculo contrariamente às intenções dos(as) evadidos(as). Para estes casos, a quem deveria ser atribuído o fracasso? Da mesma forma, nenhuma delas seria preditiva de possíveis incapacidades do(a) estudante e, 
talvez, nem da instituição. No mesmo diapasão, se se trata de uma evasão originada de uma vocação tardiamente percebida, a quem imputar o insucesso? Aliás, haveria insucesso?

Isto posto, a definição oferecida apresenta insuficiências, pois não diagnostica bem o fenômeno, não consegue identificar nele um problema público concreto, não orienta adequadamente políticas públicas para seu enfrentamento, não reflete a realidade das perdas de vínculo e assenta-se em uma construção paradoxal. O que emerge da mensuração do fenômeno assim definido seria uma realidade diferente da existente, um viés, um simulacro. E, assim, pode-se atestar que os problemas levantados por Tinto (1975) para boa parte da bibliografia especializada no fenômeno da evasão podem ser encontrados no documento do INEP, quais sejam: a inadequada atenção dada à definição e a ausência de um modelo teórico longitudinal, ambas levando à indiferenciação dos casos, à incapacitação de diagnósticos e à imobilização das políticas públicas.

\section{CONSIDERAÇÕES FINAIS}

Ao tomar como objeto de análise a definição de evasão presente no documento "Metodologia de Cálculo dos Indicadores de Fluxo da Educação Superior", publicado pelo INEP em 2017, percebeu-se que quatro problemas poderiam ser responsáveis por dificultar os diagnósticos e prognósticos da educação superior no Brasil.

Inicialmente, a opção por identificar a evasão a qualquer perda de vínculo com a educação superior, ignorando as causalidades, gerou um levantamento que coloca na rubrica da evasão fenômenos muito distintos. A indistinção não permite um diagnóstico preciso e impede o enfrentamento dos casos que devem ser tratados como problema. Da mesma forma, a definição vigente e oficial toma a evasão como uma ação definitiva, ignorando os reingressos e os múltiplos vínculos. Aqui fica patente a importância de se utilizarem estudos longitudinais para precisar o que de fato deve ser nominado como evasão e reconhecido como problema.

Outro aspecto relevante diz respeito à associação imediata da evasão ao insucesso acadêmico, sem mediações necessárias capazes de perceber que a educação superior tem finalidades que suplantam o cumprimento dos créditos e a diplomação.

Por fim, a definição mergulha num paradoxo ao excluir do cômputo da evasão os casos de falecimento em virtude de sua natureza fortuita, esquecendo que tal exclusão é, na verdade, um exercício de identificação de causalidade da perda do vínculo, justamente o que o documento do INEP não desejava fazer.

Isto posto, parece importante concluir que será necessária uma revisão do conteúdo da definição de evasão, para que ela possa exprimir mais adequadamente a realidade, instrumentalizar melhor os mecanismos de diagnósticos, capacitar a gestão pública a identificar o que são os verdadeiros problemas e agir sobre eles, sempre à luz do que estabelece a Lei de Diretrizes e Bases da Educação quanto às finalidades da educação superior. A urgência da revisão deve-se também ao fato de que, como se viu, o volume da evasão/diplomação tem sido utilizado como variável importante para balizar políticas públicas e o próprio financiamento da educação federal e, dentro dela, da assistência estudantil.

\section{REFERÊNCIAS}

BAGGI, Cristiane A. S.; LOPES, Doraci A. Evasão e avaliação institucional no ensino superior: uma discussão bibliográfica. Avaliação: Revista da Avaliação da Educaşão Superior, v. 16, n. 2, 2011.

BRASIL. Constituição (1988). Constituição da República Federativa do Brasil. Brasília, DF: Centro Gráfico, 1988.

BRASIL. Decreto n 6.096, de 24 de abril de 2007. Institui o Programa de Apoio a Planos de Reestruturação e Expansão das Universidades Federais - REUNI. Brasília, 2007 a.

BRASIL. Decreto $n^{\circ} 7.233$, de 19 de julho de 2010. Dispõe sobre procedimentos orçamentários e financeiros relacionados à autonomia universitária, e dá outras providências. Brasília, 2010. 
BRASIL. Decreto n 7.234 de 29 de julho de 2010. Dispõe sobre o Programa Nacional de Assistência Estudantil - PNAES. Brasília, 2010 b.

BRASIL. Lei no 9.394, de 20 de dezembro de 1996. Estabelece as diretrizes e bases da educação nacional. Brasília, 1996.

BRASIL. Lei ñ 10.861, de 14 de abril de 2004. Institui o Sistema Nacional de Avaliação da Educação Superior - SINAES e dá outras providências. Brasília, 2004.

BRASIL. Lei no 13.005, de 25 de junho de 2014. Aprova o Plano Nacional de Educação - PNE e dá outras providências. Brasília, 2014.

BRASIL. Ministério da Educação. Gabinete do Ministro. Portaria Normativa nº 39, de 12 de dezembro de 2007. Institui o Programa Nacional de Assistência Estudantil - PNAES. Brasília, 2007 b.

BRASIL. Ministério da Educação. Gabinete do Ministro. Portaria nº 651, de 24 de julho de 2013. Matriz Outros Custeios e Capital. Brasília, 2013.

BUENO, José Lino O. A evasão de alunos. Paidéia, Ribeirão Preto, n. 5, p. 9-16, 1993.

COIMBRA, Camila L.; COSTA, Natália Cristina D.; SILVA, Leonardo B. A evasão na Educação Superior: definições e trajetórias. Educaşão e Pesquisa, v. 46, 2020.

CROSARA, Daniela de M.; SILVA, Leonardo B. (Eds.). Assistência estudantil em debate: análise dos projetos de lei em tramitação no congresso nacional brasileiro. Curitiba: Brazil Publishing, 2020.

FONAPRACE/ANDIFES. Plano Nacional de Assistência Estudantil. ANDIFES, 2007. Disponível em: http://www.andifes.org.br/wp-

content/files_flutter/Biblioteca_071_Plano_Nacional_de_Assistencia_Estudantil_da_Andifes_comple to.pdf. Acesso em: 10 out. 2009

FREITAS, Rafael S. A ocorrência da evasão do ensino superior: uma análise das diferentes formas de mensurar. Dissertação (Mestrado). Campinas: Universidade Estadual de Campinas, 2016.

INEP. Censo da Educação Superior - 2010. Governamental. Disponível em: http://portal.inep.gov.br/web/guest/microdados. Acesso em: 11 jun. 2020.

INEP. Censo da Educação Superior - 2012. Governamental. Disponível em: http://portal.inep.gov.br/web/guest/microdados. Acesso em: 11 jun. 2020.

INEP. Metodologia de Cálculo dos Indicadores de Fluxo da Educação Superior. INEP, Brasília, 2017. Disponível em:

http://download.inep.gov.br/informacoes_estatisticas/indicadores_educacionais/2017/metodologia_i ndicadores_trajetoria_curso.pdf. Acesso em: 26 mar. 2020

INEP. Censo da Educação Superior - 2017. governamental. Disponível em: http://portal.inep.gov.br/censo-da-educacao-superior. Acesso em: 10 dez. 2018.

INEP. IDD - Indicador de Diferença entre os Desempenhos Observado e Esperado. Oficial. Disponível em: http://portal.inep.gov.br/educacao-superior/indicadores-de-qualidade/indicador-de-diferenca-entreos-desempenhos-observado-e-esperado-idd. Acesso em: 27 abr. 2020. 
JANNUZZI, Paulo de M. Indicadores sociais no Brasil: conceitos, fontes de dados e aplicações. Campinas: Editora Alínea, 2001.

LIMA JUNIOR, Paulo et al. Taxas longitudinais de retenção e evasão: uma metodologia para estudo da trajetória dos estudantes na educação superior. Ensaio: Avaliação e Políticas Públicas em Educação, v. 27, n. 102, p. 157-178, 2019.

MACHADO, Fernanda M. Financiamento da assistência estudantil nas universidades federais. Temporalis, v. 17, n. 33, p. 231-253, 2017.

MARQUES, Antônio Carlos H.; CEPÊDA, Vera A. Um perfil sobre a expansão do ensino superior recente no Brasil: aspectos democráticos e inclusivos. Perspectivas: Revista de Ciências Sociais, v. 42, 2012.

MARTINS, Paulo Fernando de M.; ARAÚJO JÚNIOR, Carlos Alberto M.; RODRIGUES, Jacqueline A. Orçamento público para financiamento da assistência estudantil no ensino superior sob a perspectiva do direito humano fundamental à educação/Public budget for the financing of student assistance in higher education. Revista Argumentos, v. 16, n. 2, p. 138-164, jul./dez. 2019.

MEC. Resoluções do CNE. Oficial. Disponível em: http://portal.mec.gov.br/conselho-nacional-deeducacao/atos-normativos--sumulas-pareceres-e-resolucoes?id=12816. Acesso em: 17 set. 2020.

RISTOFF, Dilvo Ilvo. Considerações sobre evasão. In: RISTOFF, Dilvo Ilvo. Universidade em foco: reflexões sobre a educação superior. Florianópolis: Insular, 1999, p. 119-130.

SECCHI, Leonardo. Análise de políticas públicas: diagnóstico de problemas, recomendação de soluções. São Paulo: Cengage Learning, 2016.

SESU/MEC; ANDIFES; ABRUEM. Diplomação, retenção e evasão nos cursos de graduação em IES públicas. Brasília: MEC/ANDIFES, 1996.

SILVA, Leonardo B. et al. Perfil da evasão e da retenção de estudantes dos cursos de Ciências Humanas e Ciências Biomédicas. PROSSIGA. Uberlândia: Universidade Federal de Uberlândia/Pró-reitoria de Graduação, 2019.

TCU; MEC. Orientações para o cálculo dos indicadores de gestão - Decisão TCU no 408/2002-

PLENÁRIOTCU, 2004. Disponível em: http://portal.mec.gov.br/sesu/arquivos/pdf/indicadores.pdf. Acesso em: 7 jul. 2019

TINTO, Vincent. Dropout from higher education: A theoretical synthesis of recent research. Review of educational research, v. 45, n. 1, p. 89-125, 1975.

VELLOSO, Jacques. Universidade na América Latina: rumos do financiamento. Cadernos de Pesquisa, n. 110, p. 39-66, 2000.

VIANA, Mariana Marilack Gomes. Trajetórias de cotistas negros(as): correlações improváveis entre evasão universitária e permanência no ensino superior. Dissertação (Mestrado). Belo Horizonte: Universidade Federal de Minas Gerais, 2020. 